\title{
Tabus Linguísticos nas Designações Referentes ao Corpo Humano, na Jlha dos Valadares, Paranaguá-PR
}

Linguistic Taboos in Designations Relating to Human Body, on the Island of Valadares, Paranaguá-PR

\section{Cláudia SALES DE OLIVEIRA *}

Resumo: Este trabalho tem por objetivo desenvolver uma reflexão sobre tabus linguísticos, envolvendo o corpo humano - partes do corpo e fluidos corporais - seios/peito, pênis, vagina, urina, menstruação, cheiro nas axilas, meleca/tatu. O estudo fundamentou-se na concepção de tabu estabelecida por Guérios (1956), Ullman (1977) e Kröll (1984). O estudo foi baseado em 50 questões do Questionário SemânticoLexical do Projeto ALiB (2001) e cinco elaboradas especificamente para este estudo, aplicadas para o Estudo da Variação Lexical do Português Falado na Ilha dos Valadares, Paranaguá-PR. Para o levantamento dos dados, foram selecionados 28 informantes oriundos de cinco bairros da Ilha: Vila Nova, Vila Bela, Sete de Setembro, Rocio e Itiberê, de ambos os sexos. De acordo com os resultados, além de diferentes estratégias de substituição do termo tabuizado (eufemismos e disfemismos), os informantes manifestavam reações várias para livrarse do desconforto causado pelo tabu, como risos, seriedade, recusa da resposta, reprovação, silêncio.

Palavras-chave: Variação lexical. Tabu linguístico. Corpo humano.

Abstract: This paper aims to develop a reflection on linguistic taboos involving the human body - body parts and bodily fluids - breast / chest, penis, vagina, urine, menstruation, underarm odor, slime /

* Professora no Departamento de Letras da Faculdade de Filosofia, Ciências e Letras de Paranaguá-FAFIPAR. Contato: clasaloli@yahoo.com.br 
armadillo. The study was based on the concept of taboo established by Guérios (1956), Ullman (1977) and Kroll (1984).The study was based on 50 questions of Questionnaire Lexical-Semantic ALiB Project (2001) and five developed specifically for this study, applied for the Study of Lexical Variation in the Spoken Portuguese Island of Valadares, Paranaguá-PR. For the survey data, 28 informants were selected from five districts of the island: Vila Nova, Bela, Sete de Setembro, Rocio and Itiberê, of both sexes. According to the results, and different strategies to replace the taboo term (euphemisms and dysphemisms), informants expressed various reactions to get rid of the discomfort caused by the taboo, like laughter, seriousness, refusal to answer, repetition, silence.

Key-words: Lexical variation. Linguistic taboo. The human body.

\section{Introdução}

É difícil imaginar que a sociedade humana moderna, que tem conquistado tantos avanços tecnológicos e científicos ao longo de sua história, possa manifestar superstições e tabus linguísticos. É comum direcionar a prática de tabu a civilizações do passado ou a grupos tribais isolados. No entanto, é provável que o tabu esteja tão vivo em nossa sociedade atualmente como esteve em tempos passados. Temas e palavras tabuizantes ainda causam desconforto e muitas vezes constrangimentos.

A palavra tabu tem sua origem nas línguas polinésias, ou como destaca Guérios (1956, p. 13), "de línguas do ramo malaio-polinésico, por sua vez da família munda-polinésica”. Ressalta, também, que o termo apresenta correspondentes em outros idiomas: tapu; tabu; tambu; kabu; kapu. Conforme a natureza, as palavras tabus podem ter representações diferentes, como por exemplo, "sabi (tribos ocidentais da Nova Guiné); poto, 'tabu referente a ações’ e koin, 'tabu referente a coisas e a lugares’ (entre os Alfuras da ilha Buru, índias Orientais Holandesas)" (GUÉRIOS, 1956, p. 14).

No entanto, muitas vezes a palavra tabu está associada a um comportamento considerado inadequado ou proibido, envolvendo superstições e poderes sobrenaturais. Guérios $(1956$, p. 7) ressalta a 
relação dos tabus linguísticos às palavras que, ao serem exteriorizadas podem ter "forças sobrenaturais benéficas ou maléficas"; no entanto, determinadas palavras não devem ser pronunciadas, para que não tragam "malefícios dos mesmos poderes".

Em seus estudos sobre os tabus linguísticos, Guérios (1956, p. 13) apresenta onze tipos de tabus em língua portuguesa:

$\left.1^{\circ}\right)$ tabus em nomes de pessoas; $\left.2 .^{\circ}\right)$ tabus em nomes de parentes; $3 .^{\circ}$ ) tabus em nomes de autoridades; $4 .^{\circ}$ ) tabus em nomes religiosos (teônimos, hierônimos, etc.); $5 .^{\circ}$ ) tabus em nomes de mortos; $6 .^{\circ}$ ) tabus em nomes de animais; $7 .^{\circ}$ ) tabus em nomes dos membros do corpo humano; $8 .^{\circ}$ ) tabus em nomes de lugares e circunstanciais; $\left.9 .^{\circ}\right)$ tabus em nomes de doenças e defeitos físicos); $10 .^{\circ}$ ) tabus em nomes de alimentos; e $\left.11 .^{\circ}\right)$ tabus em nomes vários.

Ullmann (1966, p. 245), por sua vez, indica que os tabus linguísticos se originam de três fontes: o medo advindo da religião e das superstições; assuntos delicados ou desagradáveis, como a doença e a morte; e atos que transgridam as leis da decência e do decoro, como as que incluem referências sexuais. Com base nesse critério, classifica assim os tabus linguísticos: tabus de medo ou superstição, diante de seres sobrenaturais, animais...; tabus de delicadeza, (envolvendo doenças, morte, defeitos físicos...); também, tabus de decência ou decoro, abarcando determinadas partes e funções corporais e o sexo (ULLMANN, 1977, p. 206).

Correia (1927 apud GUÉRIOS, 1956, p. 14), ao abordar a questão dos tabus, ressalta os atenuantes e agravantes do caráter agressivo, ofensivo e indesejável dos tabus, denominando os primeiros de eufemismos e os segundos de disfemismos, sugerindo, portanto, a seguinte classificação para os eufemismos: Eufemismos de superstição e de piedade - Eufemismos de decência e de pudor - Eufemismos de delicadeza e de respeito - Eufemismos de prudência e de megalomania. Quanto ao disfemismo, Pinker (2008, p. 389) destaca que este "remete aos aspectos mais desagradáveis do referente, em vez de simplesmente indicá-lo”, como o faz os eufemismos. É o caso do termo fežes, em que "as pessoas não gostam de pensar [...], do mesmo jeito que não gostam de vê-las, 
cheirá-las ou pôr a mão nelas”. Segundo o autor, uma forma de livrarse da situação indesejável consiste, primeiro, em referir-se à entidade "sem evocar emoções indesejáveis", fazendo uso dos eufemismos; e segundo, ressaltando o quão nojenta é a entidade, fazer uso dos disfemismos (ou do tabu). Segundo Pinker (2008), há dezenas de expressões referentes a fezes.

Nessa perspectiva, este trabalho procurou levantar dados que manifestassem tabu nas designações referentes ao corpo humano partes do corpo e fluidos corporais (seios/peito, pênis, vagina, urina, menstruação, cheiro nas axilas, meleca/tatu), evidenciando as estratégias de substituição e atitudes diante do termo tabuizado.

\section{Perfil Sociocultural da Ilha dos Valadares - Paranaguá - PR}

A Ilha dos Valadares é considerada, hoje, o maior e mais populoso bairro de Paranaguá. Está dividida em vários segmentos ou bairros: Vila Bela, Sete de Setembro, Itiberê, Vila Nova, Vila Rocio. A ocupação populacional da Ilha dos Valadares coincide com o processo de povoamento de Paranaguá, do mar em direção ao continente. De acordo com dados fornecidos pela Diocese de Paranaguá (apud TOLEDO, 1998, p. 8-9), no período de 1917 a 1930, período de maior fluxo migratório da região, a população de Paranaguá estava constituída por pessoas oriundas de outras cidades do Paraná (86,56\%), de Santa Catarina (3,05\%), de São Paulo (2,51\%), bem como de outros estados do Brasil (3,92\%) e de outros países (3,96\%).

Diegues (2006, p. 15) considera que a cultura caiçara, característica da Ilha dos Valadares, como parte da cultura crioula ou cabocla, é fruto do aporte cultural dos europeus, negros e índios. Nesse sentido, Torres (2009, p. 106), ao tratar do fandango como manifestação da cultura da Ilha dos Valadares, destaca a religião, o mito e a linguagem, como elementos importantes no universo caiçara da ilha. Em depoimentos coletados de habitantes da ilha, o autor observa que "o contato com a religiosidade foi o marco que o levou à busca de suas supostas raízes culturais", servindo de ponto de socialização dos habitantes.

O mito se revela por meio de histórias de assombrações, contadas e cantadas nos fandangos. A linguagem, peculiar da ilha, ocupa lugar 
ao lado da percepção e da memória na busca de respostas para a compreensão da identidade caiçara na Ilha dos Valadares. É por meio dela que os valores culturais de seus habitantes se difundem e se perpetuam. Os símbolos presentes nessa cultura traduzem o sentimento de identidade e pertencimento.

\section{Análise e Discussão dos Resultados}

Este estudo baseia-se em dados linguísticos coletados, a partir da aplicação de 50 questões do Questionário Semântico Lexical (QSL), do Projeto Atlas Linguístico do Brasil - ALiB (2001), cinco elaboradas especificamente para este estudo, com o objetivo de descrever e analisar as manifestações de tabu linguístico, envolvendo a área temática "Corpo Humano”, entre os habitantes da Ilha dos Valadares (Paranaguá-PR). Foram selecionados 28 informantes, 15 mulheres entre 20 e 75 anos; 13 homens entre 23 e 77 anos, com renda de até dois salários mínimos, e com até oito anos de escolarização.

A partir desse estudo, foi possível analisar o comportamento linguístico dos falantes em situações em que estes sofreram algum tipo de desconforto ou constrangimento no uso de determinados termos tabus, envolvendo as designações relativas ao corpo humano. Foram observados em suas respostas, as estratégias de substituição dos termos tabuizantes e suas reações comportamentais diante da pergunta que instigava o uso do tabu. Destacamos a seguir as manifestações de tabu em sete designações, distribuídas nas subáreas temáticas partes e fluidos corporais (seios/peito, pênis, vagina, urina, menstruação, cheiro nas axilas, meleca/tatu).

\section{Seio(s)/Peito(s)}

Observando os dados registrados no quadro 1, notamos que a lexia seio (21) foi a forma que alcançou o maior índice, seguida de peito (9) e mama (5). De acordo com Kröll (1984, p. 76), para nominar esta parte do corpo feminino, a lexia peito, juntamente com colo e seio, constitui "o eufemismo mais usado para designar os seios femininos". 
Quadro 1 - Frequência das variantes referentes às unidades lexicais seio/peito

\begin{tabular}{||c|c|c|}
\hline $\begin{array}{c}\text { A parte do corpo da mulher em que ela } \\
\text { amamenta os filhos? }\end{array}$ & Homens & Mulheres \\
\hline Seio (21) & 8 & 13 \\
\hline Mama (5) & 1 & 4 \\
\hline Teta (2) & - & 2 \\
\hline Peito (9) & 4 & 5 \\
\hline Mamica (3) & 1 & 2 \\
\hline Mamão (1) & 1 & - \\
\hline
\end{tabular}

Ávila (2007) destaca que teta é um disfemismo, ao passo que peito é neutro e seio é neutro mais formal. Ruano Faxas (2006), ao tratar da substituição da palavra tabu por outra "menos comprometedora", mais agradável, destaca o uso de seio ou peito em lugar de teta. Já o plural é mais preciso, porém, segundo Guérios (1956, p. 27), “o singular é mais delicado, porque apresenta uma parte do corpo no seu conjunto, que o plural - peitos, que evoca parcelas distintas dela: os seios".

Quanto às designações mama, mamica e mamão, é possível que haja entre elas uma relação semântica que remete, por um lado, ao "órgão glandular característico dos mamíferos que nas fêmeas produz leite" (mama $)^{1}$, à "rês que ainda mama" - (mamão $)^{1}$, e, por outro, faz referência ao fruto do mamoeiro, numa alusão ao seu tamanho e anatomia. Quanto à mamica, o dicionário não recorre ao termo, constituindo-se uma unidade de uso popular, cuja formação se deriva do termo mama.

\section{Pênis e Vagina}

A interdição no uso de lexias de cunho sexual constitui um dos domínios mais abordados quando se discutem tabus linguísticos. Ullmann (1977), ao classificar os três tipos de tabus, destaca os tabus de decência, que se referem a partes do corpo, principalmente aos órgãos sexuais. Quando a sexualidade está em jogo, palavras tabus

${ }^{1}$ Conceitos apresentados pelo Dicionário Houaiss (2003). 
apresentam uma referência direta a órgãos genitais, a funções corporais, a atos de intimidade e assim por diante.

Quanto às designações referentes aos órgãos genitais, destacamos as lexias relativas a pênis e vagina, conforme os quadros 2 e 3.

Quadro 2 - Frequência das variantes referentes à unidade lexical pênis

\begin{tabular}{|c|c|c|}
\hline PÊNIS & Homens & Mulheres \\
\hline Qual o nome do órgão sexual masculino? & & 8 \\
\hline Pênis (17) & 9 & 6 \\
\hline Pinto (8) & 2 & - \\
\hline Bráulio (1) & 1 & 1 \\
\hline Não respondeu (1) & - & \\
\hline
\end{tabular}

Quadro 3 - Frequência das variantes referentes à unidade lexical vagina

\begin{tabular}{|c|c|c||}
\hline $\begin{array}{c}\text { VAGINA } \\
\text { Qual o nome do órgão sexual feminino? }\end{array}$ & Homens & Mulheres \\
\hline Vagina (18) & 9 & 9 \\
\hline Perereca (1) & - & 1 \\
\hline Buceta (1) & - & 1 \\
\hline Pomba (10) & 6 & 4 \\
\hline Periquita (1) & - & 1 \\
\hline Não respondeu (1) & - & 1 \\
\hline
\end{tabular}

Quanto às lexias referentes a órgão sexual masculino, de acordo com o quadro 2, a maior frequência foi para o termo genérico pênis (17), seguido da metáfora pinto (8). A lexia bráulio foi pronunciada por um informante do sexo masculino. A informante 12, de 57 anos, recusou-se a responder, demonstrando constrangimento diante da pergunta.

Para Scerbo (1991 apud SOUZA, p. 81,), é a partir da ideia de personificação do genital, para o genital masculino, que surgem eufemismos como bráulio (1).

Das 10 ocorrências referentes à designação pomba, seis foram pronunciadas por informantes do sexo feminino e quatro por informantes do sexo masculino. $\mathrm{O}$ curioso foi que as mulheres que 
optaram por essa metáfora também usaram a metáfora pinto para o órgão masculino. Já os homens que escolheram essa designação apresentaram, para o órgão masculino, a designação genérica pênis. Foi possível perceber vergonha nos homens quando se referiam ao órgão feminino, pois a resposta às perguntas sempre vinham acompanhadas de muito riso. Isto, talvez, se deva ao fato de serem mulheres que realizavam as entrevistas. No geral, as perguntas de cunho sexual eram respondidas rapidamente. Em alguns casos, o silêncio e a recusa expressavam o rechaço do informante diante do termo tabu. As mulheres manifestavam surpresa diante da pergunta e expressavam opinião sobre o tipo de pergunta:

Ai теи Deus (Inf. 05-LMS-Fem-21anos)

Como é que é? O quê? (Inf. 08-VER-Fem-57 anos)

Com relação à lexia buceta (1), Ferraz (2003) inclui esse item lexical designativo do órgão feminino no rótulo geral de chulismo, lembrando que esta lexia seria incluída na categoria de "itens léxicos obscenos (não insultuosos).” Em nota, o autor esclarece:

Poder-se-ia dizer que todo item léxico considerado obsceno insulta naturalmente os 'ouvidos da moral e dos bons costumes'; todavia, referimo-nos aqui aos termos obscenos que não constituem agressividade verbal dirigida especificamente a determinado indivíduo (ex.: cabaço, cu, boceta, etc.). (FERRAZ, 2003, p. 156)

Ao tratar das designações relativas aos órgãos sexuais pênis e vulva - vagina, Kröll (1984, p. 81) afirma que a frequência do uso de palavras que designam esses órgãos, tanto femininos como masculinos, é "relativamente baixa"; entretanto, a variabilidade de expressões eufemísticas e disfemísticas dessas acepções "é enorme e a sua vitalidade e capacidade de renovação são muitíssimo grandes".

Sendo um campo lexical altamente tabuizado, os órgãos sexuais masculino e feminino passam a ser designados por metáforas como nomes de "animais, frutos, instrumentos musicais" (KRÖLL, 1984, p. 
82). Dentre as realizações metafóricas, o termo que apresentou maior frequência, para o órgão masculino, foi a lexia pinto, com oito ocorrências, e para o órgão feminino, as designações que apresentaram maiores índices foram as metáforas pomba, perereca e periquita (cf. quadro 3), todas acompanhadas de manifestações efusivas de risos.

Allan e Burridge (2006 apud PINKER, 2008, p. 398), estimam que, entre os ingleses, haja aproximadamente "mais de oitocentas expressões para cópula, mil para pênis, 1200 para a vagina e 2 mil para uma mulher libertina".

\section{Melecal tatu e cheiro de axilas}

As perguntas referentes à 'sujeira dura do nariz' e 'ao mau cheiro embaixo do braço’ provocaram, em todos os informantes, sensação desconfortável de nojo e vergonha, gerando um elevado e variado número de lexias e, no caso da segunda, ausência de respostas.

Conforme os quadros 4 e 5, apresentaram maior frequência as designações eufemísticas tatu (18) e cheiro de sovaco (9), respectivamente, para as perguntas sujeirinha dura que se tira do nariz com o dedo? e o man cheiro embaixo dos braços?

Mais conhecida entre os informantes, a lexia tatu, de acordo com Ferreira (2006, p. 128), tem origem etimológica na língua tupi e passou a designar a sujeirinha do nariz por analogia ou por inferência ao mamífero de mesmo nome. Isto porque, segundo Silveira (2009, p. 126), as características do animal 'tatu' - “corpo coberto por uma carapaça formada por [...] placas ósseas" (HOUAISS, 2001); "mora em toca escavada no chão" (BORBA, 2004) - estão associadas à secreção nasal seca, dura, que se encontra escondida nas fossas nasais. Este constitui mais um caso em que se recorre ao uso de metáforas de animais, como ressalta Kröll (1984), para designar palavras tabuizadas. 
Quadro 4 - Frequência das variantes referentes à unidade lexical meleca/ tatu

\begin{tabular}{|c|c|c|}
\hline $\begin{array}{c}\text { MELECA/TATU } \\
\text { A sujeirinha dura que se tira do nariz } \\
\text { com o dedo? }\end{array}$ & Homens & Mulheres \\
\hline Meleca (1) & - & 1 \\
\hline Tatu (18) & 8 & 10 \\
\hline Ranho (3) & 1 & 2 \\
\hline Cera do nariz (1) & 1 & - \\
\hline Catarro (3) & 1 & 2 \\
\hline Cera (6) & 3 & 3 \\
\hline \multicolumn{2}{|r}{} \\
\hline
\end{tabular}

Quadro 5 - Frequência das variantes referentes à unidade lexical cheiro nas axilas

\begin{tabular}{|c|c|c|}
\hline $\begin{array}{c}\text { CHEIRO DE AXILAS } \\
\text { O mau cheiro embaixo dos braços? }\end{array}$ & Homens & Mulheres \\
\hline Odor (3) & 2 & 1 \\
\hline Sovaqueira (1) & 1 & - \\
\hline Catinga (1) & - & 1 \\
\hline CeCê (3) & 3 & - \\
\hline Fedor (1) & - & 1 \\
\hline Cheiro de axila (1) & - & 1 \\
\hline Axila (3) & 1 & 2 \\
\hline Não sabe (4) & 2 & 2 \\
\hline Cheiro de sovaco (9) & 6 & 3 \\
\hline Porquice (1) & - & 1 \\
\hline Sovaco (3) & - & 3 \\
\hline
\end{tabular}

Por analogia, também segundo Silveira (2009), o uso da lexia cera remete à secreção do conduto auditivo, 'cera de ouvido', 'cerume'. Houve um único caso em que um informante delimita o termo, fazendo alusão à cera de nariz:

A lexia ranho tem uma relação direta com coriza, o estado líquido ou pastoso da secreção nasal. O mesmo ocorre com catarro.

Quanto às designações para 'mau cheiro embaixo dos braços', o cheiro de sovaco (9) recebeu o maior número de menções. Embora mencionando a forma tabu sovaco como primeira designação, os 
informantes recorriam, espontaneamente, a eufemismos, como cece, ${ }^{2}$ cheiro de axila, na tentativa de amenizar o impacto negativo da palavra tabu pronunciada inicialmente. No entanto, o emprego de disfemismos - fedor, sovaqueira, porquice, catinga - provocava uma sensação desconfortável nos informantes, produzindo risos e a recusa à resposta. Em situações como essas, Teruel (2011) afirma que falantes urbanos preferem o uso de um léxico culto, científico ou neutro ao termo tabuizado.

Segundo Kröll (1984, p.74), a expressão catinga, essencialmente brasileira, refere-se ao "intenso cheiro desagradável que exalam índios e negros, alguns animais e plantas".

\section{Menstruação e xixi}

De acordo com os quadros 6 e 7, a maior frequência para "perda de sangue todos os meses" foi do termo genérico menstruação (24) e para "quando a bexiga está cheia, quer-se fazer...?", a lexia xixi (25).

Além das lexias atenuantes ciclo menstrual, fluxo e chico, os informantes apresentaram variações da genérica menstruação: mensturação, misturação, minstura, todas com uma ocorrência. Essa variação do vocábulo, segundo Monteiro (2002, p. 71), constitui "uma das muitas estratégias que o falante emprega para evitar o mal-estar causado por um tabu linguístico”.

${ }^{2}$ Cecê deriva de "cheiro de corpo", expressão cunhada pela indústria de sabonetes Unilever para substituir a palavra suor. Ela surgiu na década de 1950. Nessa época, a Unilever introduziu no mercado brasileiro o sabonete Lifebuoy. O produto tinha alto poder antisséptico e bactericida, e uma de suas qualidades, exaltada nas propagandas, era acabar com o desagradável "cheiro de corpo" e dar "completo asseio corporal". (Guia dos Curiosos. Disponível em: <http:/ /guiadoscuriosos.ig.com.br /index.php?cat_id= 53783\#24>. Acesso em: 19 jun. 2011). 
Quadro 6- Frequência das variantes referentes à unidade lexical menstruação

\begin{tabular}{|c|c|c|}
\hline $\begin{array}{c}\text { MENSTRUAÇÃ̃O } \\
\text { As mulheres perdem sangue todos os } \\
\text { meses, como se chama isso? }\end{array}$ & Homens & Mulheres \\
\hline Menstruação (24) & 12 & 12 \\
\hline Mensturação (1) & 1 & - \\
\hline Misturação (1) & 1 & - \\
\hline Minstura (1) & 1 & - \\
\hline Ciclo Menstrual (1) & - & 1 \\
\hline Fluxo (1) & - & 1 \\
\hline Chico (1) & - & 1 \\
\hline
\end{tabular}

Quadro 7 - Frequência das variantes referentes à unidade lexical xixi

\begin{tabular}{||c|c|c|}
\hline $\begin{array}{c}\text { XIXI } \\
\text { Quando a pessoa está com a bexiga } \\
\text { cheia, ela quer fazer... }\end{array}$ & Homens & Mulheres \\
\hline Xixi (25) & 10 & 15 \\
\hline Pipi (1) & 1 & - \\
\hline Urinar (3) & 2 & 1 \\
\hline $\operatorname{Mijar}(5)$ & 3 & 2 \\
\hline
\end{tabular}

O tabu gera ansiedade e a necessidade de afastar a situação que provoca medo, vergonha ou nojo, uma vez que tudo quanto é tabu envolve o sagrado, o perigoso, o interdito, a imundície, a vergonha. Nesse sentido, Monteiro (2002, p. 71-72) explica que a sensação de ansiedade é atenuada quando as pessoas substituem o termo tabu por um sinônimo, ressaltando que

não são os significados ou os referentes dos vocábulos (seres, doenças, objetos etc.) que justificam a crença nos efeitos maléficos dos tabus linguísticos. Por isso é que as pessoas usam com maior naturalidade, sem medos ou maus pressentimentos, termos conceptualmente análogos à palavra proibida. 
Em pesquisa realizada com funcionários e alunos de universidades australianas, Allan e Burridge (2006 apud PINKER, 2008, p. 42) concluíram que os termos tabus provocam as mais fortes emoções que o ser humano pode evocar. Ao expô-los a um questionário sobre "nojentices", os autores verificaram que fežes e vômitos ficaram em primeiro lugar, seguidos, em segundo lugar, de sangue menstrual (para as mulheres), urina e sêmen. Esses autores ressaltaram, porém, que, embora não haja uma correlação direta entre os termos e a vulgaridade, os termos chulos relacionados a tudo que exala do corpo estão no topo da escala dos tabus, incluindo os tabuísmos para sêmen (em inglês cum, gizzum, jizze cream).

Freud (1913-1914, p. 66), ao descrever a relação que comunidades selvagens têm com o sangue menstrual, destaca o poder mágico e até sagrado que este lhes confere, ocultando razões de cunho estético e higiênico. $\mathrm{O}$ autor assim se expressa:

Diz-se que os incontáveis regulamentos de tabu a que as mulheres das comunidades selvagens estão sujeitas durante a menstruação são devidos a um horror supersticioso ao sangue e, sem dúvida, isto constitui um de seus determinantes. Mas seria errado menosprezar a possibilidade de que neste caso o horror ao sangue sirva também a propósitos estéticos e higiênicos, que, em todo caso, são obrigados a ocultar-se atrás de motivos mágicos.

Muitas vezes a interdição da lexia urinar leva à sua substituição por vocábulos da linguagem infantil - os termos usados tal como aparecem normalmente na boca da criança xixi, pipi, etc. Os eufemismos infantis visam a atenuar a sensação de nojo que o fluido corporal provoca nas pessoas.

Os disfemismos, como mijar e mijo, causam tabu, assim como cagar, e tendem a ser substituídos pelos eufemismos urinar, urina (KRÖLL, 1984, p. 94), os quais são substituídos por expressões populares e familiares, como abrir o dique, tirar a água do joelho, mictar, verter águas, etc. 


\section{Conclusão}

Embora seja comum direcionar o tabu linguístico a tempos antigos, eles estão vivos e são muito utilizados no presente. Este trabalho analisou os tabus linguísticos referentes aos termos designativos de partes e fluidos corporais, revelados por habitantes da Ilha dos Valadares, em Paranaguá, Paraná.

Os resultados revelaram que os tabus relacionados ao corpo humano provocam diferentes estratégias para atenuar ou acentuar o termo interdito. Termos metafóricos de animais (tatu, perereca, periquita, pomba, pinto) e de fruta (mamão); a personificação do órgão (bráulio); termos que ressaltam a função e anatomia do órgão designado (mama, mamão), bem como palavras do uso infantil são usos eufemísticos que atenuam o efeito de proibição gerado pelo tabu.

Além disso, vale ressaltar a presença de tabus revelada nas reações - risos e silêncio - dos informantes, provocando as não respostas às perguntas. Nesse sentido, Richter e Isquerdo (2009) reforçam a ideia de que "se pronunciadas, certas palavras tabus podem atrair malefícios a quem as proferem e aos seus familiares, daí a omissão da resposta por parte de alguns informantes". É possível inferir, também, que a ocorrência de não respostas, principalmente por informantes homens, deve-se ao fato de mulheres terem realizado as entrevistas.

A censura que repousa nos termos tabuizados é cíclica e varia de cultura para cultura e dentro de uma mesma cultura, ao longo do tempo. Assim, a interdição produz a mudança linguística, por meio da criação de novas expressões e novos significados que substituem aqueles que causam o tabu e que, por sua vez, substituíram outros termos tabus. Assim como surgem muito rápido os disfemismos e eufemismos para conceitos tabus, assim também mudam. Daí a necessidade de um aprofundamento no tema dos tabus linguísticos e seu papel na compreensão da formação do léxico no Litoral do Paraná, analisando as motivações sócio-históricas que controlam sua constituição no espaço estudado. 


\section{Referências}

ALLAN, Keith; BURRIDGE, Kate. Forbiden words: taboo and the censoring of language. Cambridge/ New York: Cambridge University Press, 2006. Disponível em: <http://wxy.seu.edu.cn/humanities/ sociology/htmledit/uploadfile/system/20110207/ 20110207022352752.pdf>. Acesso em: 29 maio 2011.

AVILA, Luz Estela Hoyos. Cómo atenuamos las "malas palabras". 2007. Disponível em: <http://www.fundacioncultural.org/revista/ nota1_29.html>. Acesso em: 16 jun. 2011.

BORBA, Francisco da Silva et al. Dicionário UNESP do port uguês do Brasil. São Paulo: UNESP, 2004.

DIEGUES, Antonio Carlos. Cultura e meio-ambiente na região estuarina de Iguape-Cananéia-Paranaguá. In: GRAMANI, Daniella; CORREAA Joana, PIMENTEL, Alexandre (Orgs.). Museu vivo do fandango. Rio de Janeiro: Associação Cultural Caburé, 2006.

FERRAZ, Aderlande Pereira. Modalização e chulismo: a rotulação em dicionários de língua. In: ENCONTRO DO CELSUL, 5., 2003, Curitiba. Anais... Curitiba: CELSUL, 2003.

FERREIRA, Aurélio Buarque de Hollanda. Novo dicionário eletrônico Aurélio. versão 5.0. Curitiba: Positivo, 2004.

FLÓREZ, William Vargas. Caracterização hidrogeológica da Ilha dos Valadares, Paranaguá - PR. Curitiba: UFPR, 2005.

FREUD, Sigmund. Totem, tabu e outros trabalhos. v. XIII, 1913-1914. Disponível em: <http://www.planonacionaldeleitura.gov.pt/ clubedeleituras/upload/e_livros/clle000164.pdf>. Acesso em: 5 jun. 2011.

GUÉRIOS, Rosario Farani Mansur. Tabus lingüísticos. Curitiba: UFPR, 1956. 
HOUAISS, Antônio. Dicionário da Lingua Portuguesa. Rio de Janeiro: Objetiva, 2003.

KRÖLL, Heinz. O eufemismo e disfemismo no português moderno. Lisboa: Instituto de Cultura e Língua Portuguesa/Ministério de Educação, 1984.

MONTEIRO, José Lemos. Linguagem e mal-estar. Revista Mal-Estar e Subjetividade, Fortaleza, v. 2, n. 1, p. 64-78, mar. 2002.

ORTIZ ALVAREZ, Maria Luisa. Tabus lingüísticos e expressões cristalizadas. Revista Acta Semiótica et Lingüistica, v. 12, p. 115-125, 2007.

PINKER, Steven. Do que é feito o pensamento. São Paulo: Companhia das Letras, 2008. Disponível em: <http://books.google.com.br/

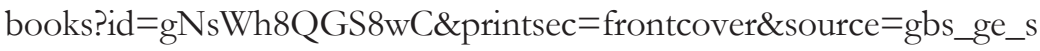
ummary_r\&cad $=0 \#_{\mathrm{v}}=$ onepage $\& \mathrm{q}=$ evocar\&f$=$ false $>$. Acesso em: 29 maio 2011.

RICHTER, Lisiane da Silva de Arruda; ISQUERDO, Aparecida Negri. Mitos e tabus linguísticos. Contribuições do Projeto ALiB. 2009. Disponível em: <http://www.propp.ufms.br/gestor/titan.php? target=openFile \&fileId=615>. Acesso em: 3 dez. 2011.

RUANO FAXAS, Fernando Antonio. Algunos recursos para valorar la comunicación a través del lenguaje oral, del lenguaje escrito y del lenguaje corporal: El área geográfica y los climas, Esferas socioculturales, Los estilos, La edad, El sexo, El tabú y la Comunicación no verbal. Ciudad de México: Ediciones BR, 2006.

SOUZA, Vivian Regina Orsi Galdino de. Vocabulário erótico-obsceno dos órgãos sexuais masculino e feminino em português e italiano. 2007. Dissertação (Mestrado em Estudos Linguísticos) - Universidade Estadual Paulista Julio de Mesquita Filho - UNESP, São José do Rio Preto. 2007. Disponível em: <http:/ / www.athena.biblioteca.unesp.br/exlibris/bd/ brp/33004153069P5/2007/souza_vrog_me_sjrp.pdf>. Acesso em: 17 jun. 2011. 
SILVEIRA, Roseli da. Estudo sociogeolingüistico do município de Iguape: aspectos semântico-lexicais. 2009. Dissertação (Mestrado em Linguística) - Universidade de São Paulo, São Paulo. 2009.

TERUEL, Fernando Carratalá. Los cambios de significado de las palabras. Disponível em: < http:/ /ontinyentcastellano.wikispaces.com/file/view/ Los_cambios_de_significado_de_las_palabras.pdf>. Acesso em: 19 jun. 2011.

TOLEDO, Adilson do Rosário. Sistema pronominal possessivo em uso na Ilha dos Valadares. 1998. Dissertação (Mestrado em Letras) Universidade Federal do Paraná, Curitiba. 1998.

TORRES, Marcos Alberto. A paisagem sonora da Ilha dos Valadares: percepção e memória na construção do espaço. 2009. Dissertação (Mestrado em Geografia) - Universidade Federal do Paraná, Curitiba. 2009. Disponível em: <http://pt.scribd.com/doc/35014307/Apaisagem-sonora-da-Ilha-dos-Valadares-Dissertacao-Marcos-TorresGeografia-UFPR-2009>. Acesso em: 3 jun. 2011.

TRUDGILL, Paul. Sociolinguistics: an introduction. Harmondsworth: Penguin, 1974.

ULLMANN, Stephen. Semantic universals. In: GREENBERG, Joseph. Universals in language. Massachusetts: MIT Press, 1966.

- Semântica: uma introdução à ciência do significado. Lisboa: Fundação Calouste Gulbenkian, 1977. 